\title{
Artikel
}

\section{Het individueel klachtrecht bij het VN-comité voor de rechten van mensen met een beperking}

\author{
Slechts toekomstmuziek of ook nu al relevant?
}

Mr. J.R.E. Stolk*

Het VN-verdrag inzake de Rechten van Personen met een Handicap (VN-verdrag Handicap) en het Facultatief Protocol (FP) bij het verdrag zijn op 3 mei 2008 in werking getreden. Nederland heeft het verdrag in 2016 geratificeerd, maar het Facultatief Protocol niet. De ratificatie van het FP laat, drie jaar na inwerkingtreding van het verdrag, nog steeds op zich wachten. Hierdoor is het individueel klachtrecht bij het VN-comité voor de rechten van mensen met een beperking (VN-comité) nog niet opengesteld voor Nederlandse burgers. Een goed moment om eens stil te staan bij de betekenis van dit individueel klachtrecht. Dit artikel zal nader ingaan op de stand van zaken met betrekking tot de ratificatie door Nederland, het individuele klachtrecht dat is neergelegd in het FP en de relevantie van de uitspraken van het VN-comité.

\section{Ratificatie van het Facultatief Protocol door Nederland}

Ten tijde van de ondertekening van het VN-verdrag Handicap heeft de Nederlandse regering besloten om het FP niet te ondertekenen en ratificeren. De reden hiervoor kan gevonden worden in de memorie van toe-

Mr. J.R.E. (Anne-Rose) Stolk is juridisch beleidsadviseur bij het College voor de Rechten van de Mens.

lichting op de Rijkswet ter goedkeuring van het VNverdrag Handicap. Hierin staat dat het FP niet is ondertekend omdat het VN-verdrag Handicap onder andere economische, sociale en culturele rechten bevat. Dit zijn rechten die vaak een positieve verplichting bevatten voor de overheid, wat wil zeggen dat ze verlangen dat de overheid iets doet om de rechten te realiseren. Deze rechten staan ook in het Internationaal verdrag inzake economische, sociale en culturele rechten (IVESCR). Toen het IVESCR werd geratificeerd is eveneens besloten om het Facultatief Protocol niet te ondertekenen, waardoor geen individueel klachtrecht mogelijk werd gemakt voor deze rechten. Om te voorkomen dat het voor mensen met een beperking wel mogelijk wordt om via de route van het $\mathrm{VN}$-verdrag Handicap een klacht in te dienen over een economisch, sociaal of cultureel recht, terwijl dit voor mensen zonder een beperking niet mogelijk is, is besloten om het FP bij het VN-verdrag Handicap niet te ondertekenen. ${ }^{1}$ Desondanks is tijdens de behandeling van de Rijkswet in de Tweede Kamer een motie ingediend die de regering verzoekt om het FP zo spoedig mogelijk te ondertekenen, omdat het onlosmakelijk met het verdrag is verbonden. ${ }^{2}$ De motie is met een meerderheid van stemmen aangenomen. ${ }^{3}$

Op verzoek van de regering heeft de Raad van State advies uitgebracht over de gevolgen van ratificatie van

Kamerstukken // 2013/14, 33992, 3, p. 6.

Kamerstukken I/ 2015/16, 33990, 38.

https://www.eerstekamer.nl/behandeling/20160121/

stemmingsoverzicht_tweede_kamer_2/document $3 / \mathrm{f}=/$

vk0xh4phcoh2.pdf. 
het Facultatief Protocol bij het IVESCR. Dit advies is nog niet openbaar gemaakt, omdat het wetsvoorstel voor de goedkeuring van het Facultatief Protocol bij het IVESCR nog niet naar de Tweede Kamer is gestuurd. ${ }^{4}$ Naar aanleiding van dit advies heeft de regering aangegeven de ondertekening en ratificatie van het FP bij het VN-verdrag Handicap aan te houden. Hier heeft de regering verschillende redenen voor gegeven. ${ }^{5}$ Zo voert de regering aan dat de financiële gevolgen voor economisch en sociaal beleid moeilijk te overzien zijn. Daarnaast is de regering voornemens om de evaluatie van toezichthoudende organen binnen de Verenigde Naties af te wachten, omdat deze evaluatie mogelijk gevolgen kan hebben voor de toezichthoudende comités, waaronder het comité bij het VN-verdrag Handicap. ${ }^{6}$

Het argument van de regering om de ratificatie van het FP bij het VN-verdrag Handicap afhankelijk te stellen van de ratificatie van het FP bij het IVESCR is overigens opmerkelijk. Nederland heeft namelijk de facultatieve protocollen bij verschillende andere verdragen, waaronder het VN-Vrouwenverdrag, wel geratificeerd. Dit terwijl het VN-Vrouwenverdrag ook economische en sociale rechten bevat. ${ }^{7}$

Drie jaar na de ratificatie van het VN-verdrag Handicap lijkt er zodoende nog geen schot te zitten in de ondertekening en ratificatie van het Facultatief Protocol. De regering is terughoudend omdat ratificatie individueel klachtrecht mogelijk maakt in zaken waarin economische of sociale rechten in het geding zijn. Hoewel het er niet naar uitziet dat het protocol op korte termijn zal worden geratificeerd, is het wel de moeite waard te onderzoeken wat de ratificatie zou betekenen. In dit artikel ga ik in op de betekenis van het individueel klachtrecht en de uitspraken van het $\mathrm{VN}$-comité over de verduidelijking en reikwijdte van het verdrag.

\section{Het individueel klachtrecht volgens het Facultatief Protocol}

Het VN-comité heeft verschillende bevoegdheden. Zo rapporteren landen die het verdrag hebben geratificeerd aan het Comité over de implementatie van het verdrag. Het Comité doet vervolgens naar aanleiding van dat rapport suggesties en algemene aanbevelingen aan de staat. ${ }^{8}$ Daarnaast heeft het Comité de bevoegdheid om een onderzoek in te stellen naar een land als er signalen zijn van grove en systematische schendingen van rech-

4. Kamerstukken I 2018/19, 35000 V, D.

5. Brief van de minister van Buitenlandse Zaken, Stand van zaken ratificatie van facultatieve protocollen bij VN-mensenrechtenverdragen, DJZ-13032019, 13 maart 2019.

6. Kamerstukken I 2018/19, 35 000, V, D.

7. Zie bijvoorbeeld: art. 12 en 13 Verdrag inzake de uitbanning van alle vormen van discriminatie van vrouwen.

8. Zie art. 35 en $36 \mathrm{VN}$-verdrag Handicap. ten die in het VN-verdrag Handicap staan. ${ }^{9}$ Een van de voornaamste bevoegdheden die het VN-comité heeft, is het in behandeling nemen van individuele klachten. Het individueel klachtrecht wordt geacht effectiever te zijn dan bijvoorbeeld de verplichting om aan het Comité te rapporteren. Dit komt omdat het in de klachtprocedure gaat om de vraag of een individu daadwerkelijk het slachtoffer is van een schending van zijn of haar mensenrechten. ${ }^{10}$ Artikel 1 FP bepaalt dat lidstaten die het Protocol hebben geratificeerd erkennen dat het VNcomité bevoegd is om individuele klachten te ontvangen en behandelen. Dit betekent niet dat iedereen zomaar een klacht kan indienen en dat die klacht vervolgens ook behandeld wordt. Hier zijn voorwaarden aan verbonden die in dit artikel zullen worden uitgelegd.

\subsection{Wie mag een klacht indienen}

In artikel $1 \mathrm{FP}$ zijn de eisen neergelegd met betrekking tot wie een klacht in mag dienen bij het $\mathrm{VN}$-comité. Het $\mathrm{VN}$-comité kan klachten ontvangen van individuen en groepen die stellen het slachtoffer te zijn van een schending van een van de rechten uit het verdrag. Er moet zodoende sprake zijn van één of meer slachtoffers. Door het vereiste dat er minimaal één slachtoffer moet zijn, is een collectief klachtrecht, zoals is opgenomen in het Europees Sociaal Handvest $(\mathrm{ESH}),{ }^{11}$ niet mogelijk bij het VN-comité. Een collectief klachtrecht zou het voor bijvoorbeeld ngo's mogelijk maken om een klacht in te dienen. Het is wel mogelijk om namens een individu of een groep een klacht in te dienen. Dit gebeurt bijvoorbeeld als een belangenorganisatie namens mensen met een beperking een klacht indient. ${ }^{12}$ Wel moet degene die namens het slachtoffer een klacht indient kunnen aantonen dat het slachtoffer hiermee heeft ingestemd. ${ }^{13}$ Het is niet ondenkbaar dat het $\mathrm{VN}$-comité in navolging van andere comités een uitzondering op deze regel creëert in het geval dat de indiener van de klacht kan aantonen dat het slachtoffer niet in staat is om zelf een klacht in te dienen. ${ }^{14}$

Slachtoffers kunnen alleen een klacht indienen tegen een land dat het FP heeft geratificeerd. Daarnaast moet degene die stelt slachtoffer te zijn zich in de jurisdictie bevinden van de staat tegen wie de klacht wordt ingediend. Met andere woorden betekent dit dat de schending heeft plaatsgevonden binnen het territorium, dus

9. Zie art. 6 FP.

10. O. Ferrajolo, 'Optional protocol to the Convention of the Rights of Persons with Disabilities', in: V. Della Fina et al. (red.), The United Nations Convention on the Rights of Persons with Disabilities. A commentary, Springer International Publishing 2017, p. 713.

11. Zie: Aanvullend protocol bij het Europees Sociaal Handvest betreffende een systeem voor collectieve klachten.

12. Zie bijvoorbeeld: Committee on the Rights of Persons with Disabilities, Communication no. 5/2011 (Marie-Louise Jüngelin v. Sweden), CRPD/C/12/D/5/2011.

13. Committee on the Rights of Persons with Disabilities, Factsheet on the procedure for submitting communications to the Committee on the Rights of Persons with Disabilities under the Optional Protocol to the Convention, CRPD/C/5/2/Rev.1, par. 7.

14. T. Stavrinaki, 'Optional Protocol to the Convention on the Rights of Persons with Disabilities', in: I. Bantekas, M.A. Stein, D. Anastasiou, The UN Convention on the Rights of Persons with Disabilities. A Commentary, Oxford University Press 2018, p. 1224. 
binnen de landsgrenzen, van de staat. Echter, verschillende mensenrechtencomités hebben het vereiste van jurisdictie breder geïnterpreteerd. Niet alleen als de gestelde schending binnen het territorium heeft plaatsgevonden, maar ook wanneer de staat effectief de controle had over het slachtoffer kan de schending binnen de jurisdictie van de staat vallen. Dit doet zich bijvoorbeeld voor als de schending plaatsvindt in bezet gebied. ${ }^{15}$

\subsection{Voorwaarden voor het indienen van een klacht}

Als het VN-comité heeft vastgesteld dat aan de eisen uit artikel 1 FP is voldaan, zal worden getoetst of aan de overige toelatingseisen is voldaan. Deze zijn neergelegd in artikel 2 FP. Als niet aan deze voorwaarden is voldaan zal de klacht niet-ontvankelijk worden verklaard, wat betekent dat het VN-comité de klacht niet in behandeling neemt.

Het eerste vereiste is dat de klacht niet anoniem is. Met andere woorden, de indiener moet geidentificeerd kunnen worden. Als onduidelijk is wie de klacht heeft ingediend, zal het secretariaat om aanvullende informatie vragen. ${ }^{16}$ De indiener van de klacht moet er daarnaast mee instemmen dat zijn of haar identiteit wordt gedeeld met de staat waartegen de klacht is ingediend. Als de indiener hier niet mee instemt, wordt de klacht niet geregistreerd. ${ }^{17}$

De tweede grond waarop het VN-comité een klacht niet-ontvankelijk kan verklaren is als misbruik wordt gemaakt van het klachtrecht of als de klacht onverenigbaar is met het Verdrag. Er kan sprake zijn van misbruik van het klachtrecht als herhaaldelijk een klacht wordt ingediend over dezelfde situatie, terwijl er geen nieuw bewijs is en het $\mathrm{VN}$-comité zich al eerder over de zaak heeft uitgelaten. ${ }^{18}$ Het vereiste dat de klacht verenigbaar moet zijn met het Verdrag betekent dat de situatie waarover wordt geklaagd binnen de reikwijdte van het VN-verdrag Handicap valt. De klacht moet dus zien op een van de rechten die in het Verdrag zijn opgenomen. ${ }^{19}$ In het verlengde van deze eis ligt het vereiste dat de klacht goed moet zijn onderbouwd en niet kennelijk ongegrond mag zijn. Dit houdt in dat de indiener de feitelijke en juridische omstandigheden voldoende moet onderbouwen. $^{20}$ Het VN-comité kan een klacht kennelijk ongegrond verklaren als de indiener artikelen van het Verdrag inroept die door hun algemene karakter geen aanleiding geven voor een individuele claim. Een voorbeeld is artikel $1 \mathrm{VN}$-verdrag Handicap. Dit artikel bevat de doelstelling van het verdrag en bevat geen rechten waarop een individu een beroep kan doen. Dit

15. Ibid., p. 1225-1226

16. Committee on the Rights of Persons with Disabilities, Rules of procedure, CRPD/C/1/Rev.1, rule 57

17. Ibid., rule 70 .

18. T. Stravinaki, p. 1228

19. Ibid.

20. O. Ferrajolo, p. 715 soort artikelen kunnen alleen in samenhang met andere rechten uit het Verdrag worden ingeroepen. ${ }^{21}$

Het VN-comité zal een klacht ook niet-ontvankelijk verklaren als de situatie al eerder door het Comité is behandeld, of als het al is behandeld of wordt behandeld onder een andere internationale procedure. Dit doet zich bijvoorbeeld voor als de klacht bij het Europees Hof voor de Rechten van de Mens (EHRM) en bij het VN-comité is ingediend. Als het EHRM de klacht vervolgens in behandeling neemt of al heeft behandeld, zal het VNcomité de klacht niet-ontvankelijk verklaren. In deze eis ligt het ne-bis-in-idembeginsel besloten dat men niet twee keer voor hetzelfde gestraft mag worden. ${ }^{22}$

Het vierde vereiste is dat de nationale rechtsmiddelen moeten zijn uitgeput. In de context van Nederland betekent dit dat tot de hoogste rechter, dus bijvoorbeeld de Hoge Raad of de Raad van State, moet zijn doorgeprocedeerd. Dit vereiste komt voort uit het principe dat staten eerst de mogelijkheid moeten krijgen om zelf eventuele schendingen recht te zetten voordat zij op internationaal niveau aansprakelijk worden gehouden. ${ }^{23}$ Het VN-comité krijgt daarmee een meer complementerende rol, wat er tevens aan bijdraagt dat ze niet overspoeld wordt met klachten. ${ }^{24}$ Een uitzondering op deze regel doet zich voor wanneer de nationale rechtsmiddelen geen uitzicht op herstel bieden of wanneer ze onnodig worden uitgesteld. ${ }^{25}$ Dit kwam ter sprake in de zaak Noble t. Australië. Australië voerde aan dat de klacht niet-ontvankelijk moest worden verklaard, omdat er nog beroep openstond tegen een uitspraak van de rechter. De indiener van de klacht stelde echter dat het instellen van beroep geen uitzicht op succes bood, omdat de uitspraak van de rechter in overeenstemming was met de wetgeving. Het VN-comité besloot dat er objectief gezien geen uitzicht was op succes en dus dat de nationale rechtsmiddelen niet uitgeput hoefden te worden. ${ }^{26}$ De laatste eis waaraan moet zijn voldaan is dat de situatie en de feiten waarover wordt geklaagd zich niet voordeden voordat het Facultatief Protocol in werking is getreden in de staat waartegen de klacht is gericht. Deze eis bevat zodoende het beginsel dat iemand niet met terugwerkende kracht aansprakelijk kan worden gehouden. ${ }^{27}$ Uitzondering op deze regel geldt wanneer de feiten nog steeds voortduren na de inwerkingtreding. Dit deed zich voor in de zaak tussen Nyusti en Takács tegen Hongarije. Het ging in deze zaak over de toegankelijkheid van geldautomaten voor mensen met een visuele beperking. Het VN-comité stelde vast dat de geldautomaten ook na de inwerkingtreding van het FP nog ontoegankelijk waren. Omdat de feiten na de inwerking-

21. Zie bijvoorbeeld: Committee on the Rights of Persons with Disabilities, Communication no. 3/2011 (H.M. v. Sweden), CRPD/C/7/D/3/2011, par. 7.3.

22. O. Ferrajolo, p. 715

23. C. Tomuschat, Human rights: between idealism and realism (3rd edition), Oxford University Press 2015, p. 256-257.

24. T. Stravinaki, p. 1230

25. Zie art. 2(d) FP.

26. Committee on the Rights of Persons with Disabilities, Communication no. 7/2012 (Noble v. Australia), CRPD/C/16/D/7/2012, par. 7.7.

27. T. Stravinaki, p. 1233. 
treding van het FP nog steeds voortduurden, was de klacht ontvankelijk. ${ }^{28}$

\subsection{Behandeling van de klacht}

Als het VN-comité heeft besloten dat de klacht ontvankelijk is, kan de zaak inhoudelijk worden behandeld. Deze procedure verloopt anders dan een juridische procedure in Nederland. Waar juridische procedures in Nederland in beginsel openbaar zijn, is dat bij het VNcomité niet het geval. ${ }^{29}$ Het $\mathrm{VN}$-comité houdt gesloten bijeenkomsten waarin het de klacht beoordeelt. ${ }^{30}$ Een ander verschil is dat de procedure schriftelijk verloopt. De partijen hoeven niet voor het $\mathrm{VN}$-comité te verschijnen, maar dienen hun stukken schriftelijk in. ${ }^{31}$

Als het VN-comité dat nodig acht, kan het de staat op grond van artikel 4 FP verzoeken om voorlopige maatregelen te nemen voordat een definitieve uitspraak is gedaan. Het verzoek om een voorlopige maatregel wordt vaak gedaan als er een risico bestaat dat de indiener van de klacht schade oploopt die niet meer teruggedraaid kan worden. Staten zijn echter niet verplicht om aan dit verzoek gevolg te geven. ${ }^{32}$

Nadat het VN-comité de klacht heeft behandeld en beoordeeld zal het suggesties en aanbevelingen doen en deze naar de staat en de indiener van de klacht toesturen. ${ }^{33}$ Deze suggesties en aanbevelingen zijn niet bindend voor de staat en kunnen dus in principe worden genegeerd. Echter, de beslissingen die verdragscomités nemen hebben wel autoriteit. Dit betekent dat er waarde wordt gehecht aan de beslissingen van het VN-comité en dat de beslissingen niet zomaar zullen worden genegeerd. Het is niet voor niets dat staten het VN-comité hebben gemandateerd om individuele klachten te toetsen aan het VN-verdrag Handicap. ${ }^{34}$ Bovendien kunnen staten de beslissing van het VN-comité niet zonder meer naast zich neer leggen. Zij moeten namelijk binnen zes maanden schriftelijk reageren op de beslissing van het Comité. In deze reactie moet tevens worden aangegeven of er actie is ondernomen naar aanleiding van de suggesties en aanbevelingen die zijn gedaan. ${ }^{35}$

Committee on the Rights of Persons with Disabilities, Communicatio no. 1/2010 (Nyusti and Takács v. Hungary), CRPD/C/9/D/1/2010, par. 8.2.

29. C. Tomuscat, p. 261.

30. Zie art. $5 \mathrm{FP}$.

31. Zie: Committee on the Rights of Persons with Disabilities, Rules of procedure, CRPD/C/1/Rev.1, rule 70

32. O. Ferrajolo, p. 717

33. Zie art. 5 FP.

34. T. Stravianki, p. 1249

35. Committee on the Rights of Persons with Disabilities, Rules of procedure, CRPD/C/1/Rev.1, rule 75 .

\section{Uitspraken van het $\mathrm{VN}$ - comité}

Op dit moment hebben 96 landen het Facultatief Protocol geratificeerd. ${ }^{36}$ Sinds de inwerkingtreding van het FP in 2008 heeft het VN-comité in 34 klachtprocedures een uitspraak gedaan. In negen daarvan heeft het Comité de klacht niet-ontvankelijk verklaard, drie zaken heeft het Comité niet verder behandeld omdat de staat tussentijds een oplossing had geboden en in 22 zaken heeft het Comité inhoudelijk een beslissing gegeven. De staten waartegen een klacht is ingediend liggen verspreid over de hele wereld, al zijn er relatief veel klachten (9) ingediend tegen Australië. Zoals eerder is uitgelegd hebben de uitspraken van het $\mathrm{VN}$-comité geen bindend effect. Daarnaast zijn de uitspraken van het VN-comité gericht aan de staat waartegen de klacht is ingediend. De uitspraken hebben dus geen effect op andere staten. Dit kan de vraag oproepen wat de relevantie is van de uitspraken van het $\mathrm{VN}$-comité voor andere landen, zoals Nederland.

De uitspraken van het VN-comité zijn niet een-op-een toepasbaar op andere, vergelijkbare situaties. Toch zijn de uitspraken wel relevant, omdat ze laten zien hoe het VN-verdrag Handicap moet worden geïnterpreteerd en verduidelijken wat van staten wordt verwacht. Het voert te ver om alle uitspraken van het VN-comite in dit artikel te behandelen. Daarom zullen ter illustratie twee uitspraken van het $\mathrm{VN}$-comité worden uitgelegd. Er is voor deze twee zaken gekozen, omdat ze ook relevant kunnen zijn voor Nederland. De eerste zaak gaat over de verkiezingen en kan van betekenis zijn voor de discussie in Nederland over de manier warop verkiezingen toegankelijk moeten worden gemaakt voor mensen met een beperking. De tweede zaak gaat over de toegankelijkheid van het openbaar vervoer en kan relevant zijn voor de toepassing van de $\mathrm{Wgbh} / \mathrm{cz}$ in zaken die over het openbaar vervoer gaan.

\subsection{Fiona Given t. Australië}

Mevrouw Given kan tijdens de verkiezingen door haar beperking niet zelfstandig haar stem uitbrengen. Alleen door gebruik te maken van een elektronisch stemapparaat zou zij anoniem en zelfstandig kunnen stemmen. Op de verkiezingsdag blijkt in het stembureau geen elektronisch stemapparaat te zijn. Daarom vraagt ze of een lid van het stembureau haar wil begeleiden en helpen tijdens het stemmen. Het stembureau-lid weigert haar te helpen en stelt dat haar begeleider haar moet helpen stemmen. Volgens Fiona Given is dit een schending van het $\mathrm{VN}$-verdrag Handicap, omdat zij niet in staat is gesteld om een stem uit te brengen met behulp van ondersteunende technologie en omdat zij niet zelf kon kiezen wie haar moest begeleiden bij het stemmen. ${ }^{37}$

36. https://www.un.org/development/desa/disabilities/convention-on-therights-of-persons-with-disabilities.html (laatst bezocht: 22 september 2019).

37. Committee on the Rights of Persons with Disabilities, CRPD/C/19/D/ 19/2014, par. 2.1-3.2 
Australië stelt dat er geen sprake is van een schending. Australië betoogt onder andere dat artikel 29 niet van staten verlangt dat zij ondersteunende technologieën aan iedere stemmer ter beschikking stellen. Het zou hier gaan om een verplichting die geleidelijk verwezenlijkt moet worden en waarbij rekening moet worden gehouden met de discretionaire bevoegdheid van staten om te bepalen hoe middelen worden verdeeld. ${ }^{38}$

Het VN-comite is het niet eens met de argumenten van Australië. Het VN-comité begint zijn overwegingen met het uiteenzetten van de verplichtingen die staten hebben onder artikel 29. Artikel $29 \mathrm{VN}$-verdrag Handicap verlangt van staten dat stemprocedures zo worden aangepast dat zij geschikt, toegankelijk en goed te begrijpen en te gebruiken zijn. De mogelijkheden die mevrouw Given had om haar stem uit te brengen, namelijk met behulp van een assistent, stelden haar niet in staat om in het geheim haar stem uit te brengen. Alleen met behulp van ondersteunende technologie had zij zelfstandig en in het geheim, en dus op voet van gelijkheid met anderen, haar stem uit kunnen brengen. De optie om elektronisch te stemmen was tijdens een eerdere verkiezing wel ter beschikking gesteld aan mensen met een visuele beperking. Australië had niet aangetoond dat het beschikbaar stellen van deze mogelijkheid tijdens deze verkiezingen een onevenredige belasting zou vormen. Daarnaast overweegt het $\mathrm{VN}$-comité dat het verbod op discriminatie ook betekent dat niet gediscrimineerd mag worden naar type beperking. De mogelijkheid om elektronisch een stem uit te brengen had zodoende ook beschikbaar moeten worden gesteld aan personen met een andere dan een visuele beperking. ${ }^{39}$

\subsection{F. t. Oostenrijk}

Een tweede zaak die interessant is om hier te bespreken is de zaak van F. tegen Oostenrijk. F. is een man met een visuele beperking die van het openbaar vervoer gebruik maakt voor zijn dagelijkse activiteiten. F. maakt veelvuldig gebruik van een specifieke tramlijn waarbij tot 2011 bij elke halte een audiosysteem was geïnstalleerd dat de actuele reisinformatie kon voorlezen. Dit audiosysteem maakt het mogelijk voor F., en andere reizigers met een visuele beperking, om zelfstandig en op voet van gelijkheid met anderen te reizen. In 2011 wordt de tramlijn die F. altijd gebruikt, uitgebreid. Bij geen van de nieuwe haltes wordt het digitale audiosysteem geinstalleerd. Volgens F. is dit een schending van artikel 5 en 9 VN-verdrag Handicap, omdat de informatie niet toegankelijk is voor mensen met een visuele beperking en hij daardoor niet op voet van gelijkheid met anderen gebruik kan maken van het openbaar vervoer. ${ }^{40}$

Oostenrijk voert aan dat geen sprake is van een schending van het VN-verdrag Handicap. De afwezigheid van het audiosysteem heeft geen belemmerende werking op het gebruik van het openbaar vervoer, omdat de informatie ook via het internet beschikbaar is. Mensen met

38. Ibid., par. 4.9-4.11

39. Ibid., par. 8.9.

40. Committee on the Rights of Persons with Disabilities, CRPD/C/14/D/ 21/2014, par. 2.1-3.1 een visuele beperking kunnen zodoende via het internet alle benodigde informatie tot zich nemen, wat een goed alternatief is voor informatievoorziening door middel van een digitaal audiosysteem. Daarnaast voert Oostenrijk aan dat het VN-verdrag Handicap staten niet verplicht om het openbaar vervoer met alle mogelijke voorzieningen uit te rusten om het gebruik ervan te faciliteren, maar dat het de dienstverlener vrijstaat om een keuze te maken tussen alternatieven. ${ }^{41}$

Het VN-comité is het niet eens met deze argumenten. Het digitale audiosysteem was bekend bij de vervoersorganisatie en had dan ook zonder veel extra kosten kunnen worden geinstalleerd bij de nieuwe tramhaltes. Omdat het audiosysteem niet is geinstalleerd bij de nieuwe haltes hebben meneer $\mathrm{F}$. en andere reizigers met een visuele beperking niet op voet van gelijkheid met anderen toegang tot informatie. De alternatieve manieren waarop reizigers met een visuele beperking de informatie tot zich konden nemen zijn niet voldoende om dit te waarborgen. ${ }^{42}$

\subsection{Relevantie van de uitspraken}

Wat deze uitspraken allereerst laten zien is dat ze over situaties gaan waar mensen met een beperking in het dagelijks leven tegenaan lopen. Dit bevestigt ook wat in de preambule van het VN-verdrag Handicap staat. Namelijk dat mensen met een beperking ondanks allerlei initiatieven en uiteenlopende instrumenten nog steeds geconfronteerd worden met obstakels die hun participatie in de samenleving als gelijkwaardige leden belemmeren. Het is dus ook niet ondenkbaar dat mensen met een beperking in Nederland met dit soort situaties geconfronteerd kunnen worden. Met betrekking tot de verkiezingen is bijvoorbeeld bekend dat mensen met een beperking nog steeds obstakels ervaren. ${ }^{43}$

De zaken tussen Fiona Given en Australië en F. en Oostenrijk verschillen op veel vlakken. Toch zijn er ook overeenkomsten zichtbaar als naar de beoordeling door het VN-comité wordt gekeken. Zo nemen de grondbeginselen van het Verdrag in beide zaken een belangrijke plaats in. Beginselen als autonomie, participatie, gelijke kansen en toegankelijkheid komen in beide uitspraken terug. Dat het VN-comité de grondbeginselen een belangrijke plaats geeft in zijn beoordeling toont het belang van deze beginselen aan. Het is aan staten om deze beginselen ook een belangrijk onderdeel te laten zijn van het beleid en de wetgeving die zij ontwikkelen.

De uitspraken laten ook zien dat staten altijd voor de optie moeten kiezen die er het meest aan bijdraagt dat mensen met een beperking op voet van gelijkheid kunnen participeren in de samenleving. In beide zaken voerde de staat aan dat er alternatieven beschikbaar waren die het mogelijk maakten om respectievelijk een stem uit te brengen en reisinformatie te verkrijgen. Voor het VN-comité was dit niet voldoende, nu in beide

41. Ibid., par. 4.7-4.9.

42. Ibid., par. 8.7 .

43. https://www.mensenrechten.nl/nl/nieuws/meldpunt-onbeperktstemmen-meeste-meldingen-over-toegankelijkheid-stemlokalen-enhulp-bij (laatst bezocht: 23 september 2019). 
landen ook een optie beschikbaar was die de zelfstandigheid van personen met een beperking en de gelijkheid ten opzichte van anderen zou vergroten. Halve maatregelen zijn dus niet voldoende. Als er een beter alternatief beschikbaar en voorhanden is, zal voor die optie gekozen moeten worden.

\section{Conclusie}

Op dit moment lijkt de ratificatie van het Facultatief Protocol door Nederland nog toekomstmuziek. Wanneer Nederland overgaat tot ratificatie van het Facultatief Protocol maakt dit het individueel klachtrecht mogelijk bij het VN-comité. Individuen of groepen kunnen dan een klacht indienen over vermeende schendingen van het $\mathrm{VN}$-verdrag Handicap. Het indienen van een klacht gaat niet zomaar. Er moet aan verschillende eisen worden voldaan voordat het $\mathrm{VN}$-comité de klacht in behandeling neemt. Hoewel de beslissing van het Comité niet bindend is, heeft het wel autoriteit. Daarnaast wordt van staten verlangd dat zij door middel van een follow-up aan het Comité kenbaar maken wat ze met de beslissing hebben gedaan. Dat Nederland het Facultatief Protocol nog niet heeft geratificeerd, betekent niet dat de uitspaken van het Comité geen relevantie hebben. Ze verduidelijken hoe het $\mathrm{VN}$-verdrag Handicap moet worden geïnterpreteerd en laten zien wat van staten wordt verwacht als het gaat om de implementatie van het verdrag. 